\title{
Gamma Irradiation-induced Variation in Carrots (Daucus carota L.)
}

\author{
Bassam Al-Safadi ${ }^{1}$ and Philipp W. Simon ${ }^{2}$ \\ Vegetable Crops Research Unit, U.S. Department of Agriculture, Agricultural Research Service, \\ Department of Horticulture, University of Wisconsin, Madison, WI 53706
}

Additional index words. mutagenesis, somaclonal variation

\begin{abstract}
Carrot tissue cultures, germinating seed, and dry seed were exposed to gamma radiation. Irradiation accelerated germination of carrot seed in the $M_{1}$ generation at low doses $(0.5$ and $1 \mathrm{krad})$, whereas higher doses delayed germination. A high negative correlation was observed between dose and survival of plants after seed irradiation. Plant size and root weight were $20 \%$ to $35 \%$ greater than control plants after seeds, but not tissue cultures, were exposed to low doses of gamma irradiation. Higher doses reduced $M_{1}$ plant size by $>50 \%$ in germinating seed and tissue culture treatments but less for the dry seed treatment. Seed production decreased while phenotypic variation of $M_{1}$ plants increased with increasing gamma ray dosage. Root weight and total dissolved solids were highly variable in $M_{2}$ families. Less variation was observed in total carotene content and none was seen in sugar type (reducing vs. nonreducing sugars). Induced variation in root color and root shape was also observed. Irradiation of germinating seed and tissue cultures yielded more $M_{2}$ variation than irradiation of dry seed. Putative point mutations were not observed. Unirradiated carrot tissue cultures did not yield significant $M_{2}$ somaclonal variation. Average root weight of $M_{2}$ plants increased with increasing gamma ray dosage, especially for the dry seed treatment.
\end{abstract}

Induced mutations have effectively increased genetic variability, which in turn is useful in plant breeding, since mutagenesis can yield variation in an otherwise fixed genetic background. More than 1200 cultivars have been produced by mutation breeding (IAEA, 1989).

There have been a few studies on carrot mutagenesis (Estramareix et al., 1986; LoSchiavo et al., 1983, 1989; Miller et al., 1984; Sung, 1976; Templeton-Somers et al., 1981), and most of the changes were observed at the molecular or cellular levels and not in whole plants. The objectives of this study were to 1) investigate the effects of gamma irradiation on the germination of $M_{1}$ carrot seed and the survival and growth of plants from tissue culture and seed and 2) study the phenotypic and biochemical variation in $\mathrm{M}_{2}$ plants from irradiated carrot tissue cultures and seed.

\section{Materials and methods}

Plant materials and irradiation. Plant materials used for irradiation (carrot tissue cultures and seed) used in this study came from inbred carrot line B493 (Simon et al., 1990). Carrot tissue cultures were initiated, grown, and irradiated as previously described (Al-Safadi and Simon, 1990). Carrot seeds were irradiated either dry or while germinating. For the germinating seed experiment, seeds were soaked in $0.52 \%$ sodium hypochlorite for $15 \mathrm{~min}$, washed three times with distilled water, placed on moistened filter papers in petri dishes in the dark at $21^{\circ} \mathrm{C}$, and allowed to germinate. Five days later, all seeds (germinating and nongerminating) were irradiated. Dry seeds were sterilized with sodium hypochlorite solution and washed $1 \mathrm{~h}$ before irradiation. Seeds from both experiments were exposed to gamma irradiation with doses ranging from 0.5 to $40 \mathrm{krads}$. In both experiments, two replications of 200 seeds were used for each dose and for the control.

Received for publication 28 Aug. 1995. Accepted for publication 7 Mar. 1996. The cost of publishing this paper was defrayed in part by the payment of page charges. Under postal regulations, this paper therefore must be hereby marked advertisement solely to indicate this fact.

${ }^{1}$ Graduate research assistant. Permanent address: Syrian Atomic Energy Commission, P.O. Box 6091, Damascus, Syria.

${ }^{2}$ Research geneticist and professor.

\section{Survival determination}

Dry seed experiment. Germinating seeds (cotyledon emergence) were counted daily while on petri dishes for 1 week after the first seed germinated ( $3 \mathrm{~d}$ after irradiation). Seedlings were then transferred to sterile vermiculite in the greenhouse. After 2 weeks, emerging seedlings were counted as survivors.

Germinating seed experiment. After irradiation, germinating seeds were planted in sterile vermiculite and treated as before. Surviving plants in both experiments were transferred to soil (1 peatmoss : 1 sand : 1 compost soil) and grown in the greenhouse.

Tissue culture experiment. Carrot plants (100 for each dose and for control) were regenerated from tissue cultures by means of organogenesis and embryogenesis (Al-Safadi and Simon, 1990). Regenerated plants were transferred to soil ( 1 peatmoss : 1 sand : 1 compost soil) in jars under $16 \mathrm{~h}$ light and $8 \mathrm{~h}$ dark at $25^{\circ} \mathrm{C}$. Growing plants were transferred 4 weeks later to small pots and grown in the greenhouse. Two weeks later, surviving plants were counted. After 3 months, surviving $M_{1}$ plants for all experiments were counted and harvested, and plant length (from leaf tip to storage root tip) was recorded. Foliage was trimmed to 2 to $4 \mathrm{~cm}$, roots were washed and dried, and fresh weights were taken.

$M_{1}$ phenotypic variation. Vernalized $\mathrm{M}_{1}$ plants growing in the greenhouse were scored for phenotypic variation. All surviving plants were included. The variation included differences in plant appearance (leaf length, shoot number, and plant height), flower morphology, and leaf color (darker or lighter than the control). Variation in flower morphology and leaf color were evaluated by visual inspection, whereby plants were scored as variants if flower morphology or leaf color were noted as unusual in all of at least three independent evaluations of plants during early stages (2 months) of flowering.

Production of $M_{2}$ seed and roots. After weighing, $\mathrm{M}_{1}$ plants were vernalized, planted, and self-pollinated as described (Simon and Peterson, 1984) to produce $\mathrm{M}_{2}$ seeds. Seed production was measured as percentage of plants producing germinable seed. Seed was planted on 10-15 May on muck soil at Palmyra, Wis., in a completely randomized design. Plots were thinned to equalize stands. About $100 \mathrm{M}_{2}$ seeds from every selfed plant were planted in 12-foot rows. After the plants were grown for 3 months, survival 


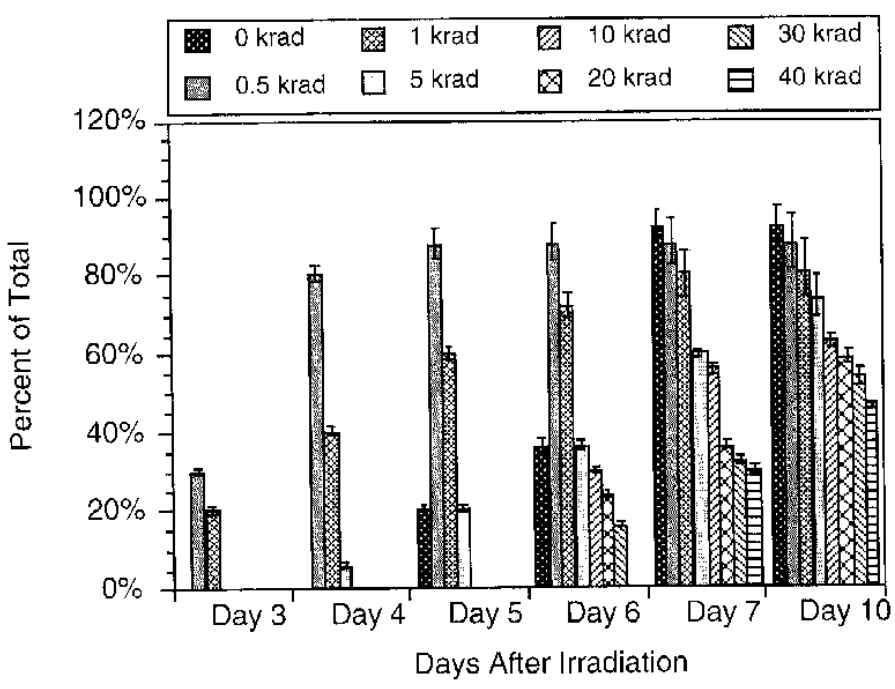

Fig. 1. The cumulative germination rate of gamma-irradiated dry carrot seed. Mean values \pm standard error.

and leaf phenotypic variation were noted and the roots were harvested. After the 12-18 Aug. harvest, tops were removed and roots were washed, individually weighed, and scored for phenotypic variation (internal and external color, length, and width), and samples were taken for sugar and carotene analysis.

Laboratory evaluations. Percentage total dissolved solids (TDS) was determined as described by Stommel and Simon, 1989. Reducing sugar content was estimated as described (Simon and Freeman, 1985). Carotene was extracted from freeze-dried samples with hexane and quantified as described by Simon and Wolff, 1987.

Statistical analysis. Linear regression analysis was used to determine the correlation between radiation dose and response of carrot tissue cultures and seed to radiation. Analysis of variance and Fisher's LSD tests were used to determine if the observed variations were significantly different from the control.

\section{Results}

\section{$M_{1}$ variation}

Significant effects of radiation on seed germination, plant survival, and plant size were noted.

Germination of irradiated dry seeds. Seed germination was

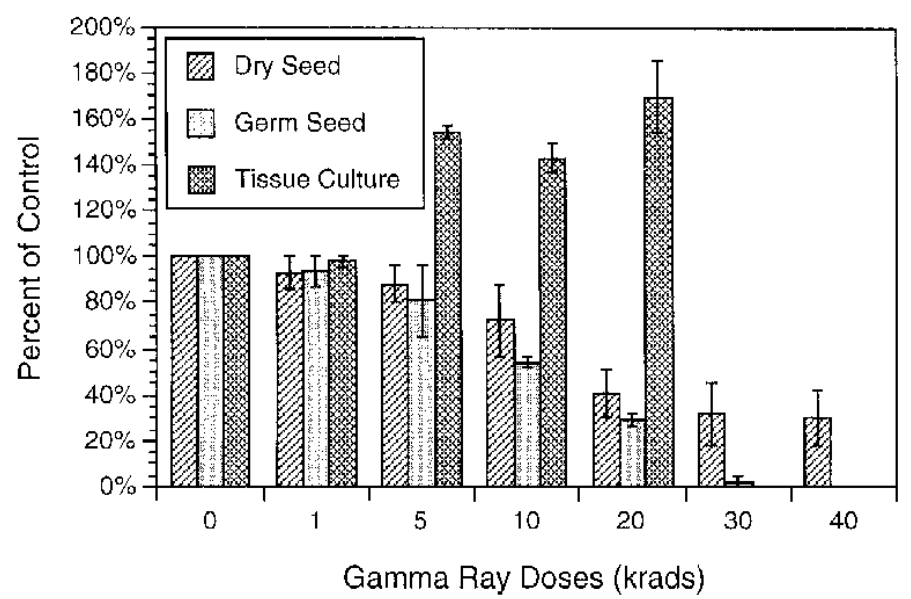

Fig. 2. The effects of gamma irradiation on the survival of $M_{1}$ carrot plants in the greenhouse. All values are adjusted to a percent of control. Mean values 土standard error. most rapid with $0.5 \mathrm{krad}$ radiation where $30 \%$ of the seeds had germinated at day $3,80 \%$ at day 4 , and $88 \%$ at day 5 (Fig. 1). Only $20 \%$ of the control seeds germinated at day 5 , but by day 7 levels had reached $90 \%$. Some stimulation was also observed at the 1krad dose. Higher doses delayed seed germination especially at the $40-\mathrm{krad}$ dose, at which no germination was observed until the seventh day after irradiation. After $10 \mathrm{~d}$ no further seed germination was observed.

Survival of plants. Survival was recorded 2 weeks after irradiation. A high negative correlation $(r=0.98, P<0.01)$ between dose and percentage of surviving plants was observed in dry and germinating seed experiments. The effects of radiation on germinating seeds were more severe than on dry seeds (Fig. 2). For example, only $4 \%$ of the plants irradiated as germinating seed survived at the $30-\mathrm{krad}$ treatment, whereas $30 \%$ of the dry seed survived (Fig. 2). On the other hand, more plants regenerated from irradiated tissue cultures survived the greenhouse conditions than the control for treatments up to $20 \mathrm{krad}$. A dosage of $30 \mathrm{krad}$ was lethal to carrot tissue culture and germinating seed.

Root weight. Root weights were also measured 3 months after irradiation (Fig. 3). Root weight was increased by about 35\% above the control at the 1-krad dose in the dry seed experiment and $18 \%$ in the germinating seed experiment. No increase in root weight was observed in plants regenerated from irradiated tissue cultures. Doses $>5 \mathrm{krad}$ decreased the root size significantly, especially in the germinating seed, where it decreased to only $22 \%$ of the control at the 20-krad dose.

Phenotypic variation and seed production. Phenotypic variation significantly increased with increasing gamma ray dosage (data not presented). The least variation occurred in plants growing from irradiated dry seed, with most in irradiated plants from tissue culture. In the tissue culture experiment, there was $\mathbf{M}_{1}$ variation even in the control plants, although more was observed with irradiation. With this increased phenotypic variation there was a simultaneous decrease in seed production (Fig. 4). Percentage of plants producing seed was only $45 \%$ of total plants in the tissue culture experiment, $53 \%$ in the germinating seed experiment, and $70 \%$ in the dry seed experiment at the 20-krad dose. Pollen stainability and in vitro germination declined with increasing irradiation comparable to seed production of plants irradiated as germinating seed (data not presented).

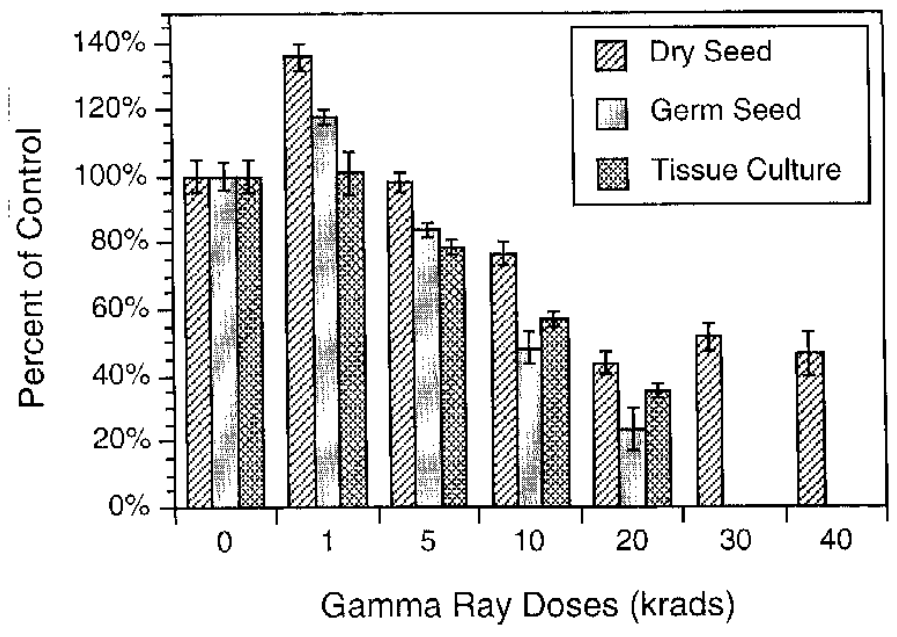

Fig. 3. The effects of gamma irradiation on the root weight of mature $M_{1}$ carrot plants. All values are adjusted to a percent of control. Mean values \pm standard error. Control value $=29.7 \mathrm{~g}$. 


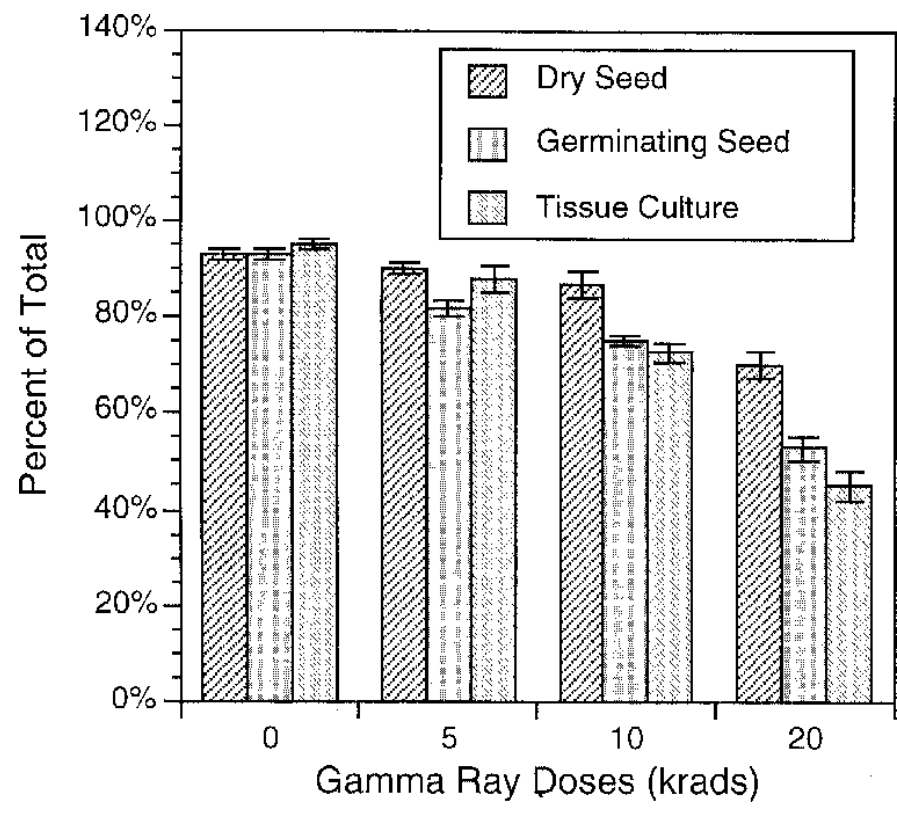

Fig. 4. The effects of gamma irradiation on percent of plants producing germinable seed in $M_{1}$ carrot plants derived from dry seed, germinating seed, and tissue cultures. Values represent the means of treatments \pm standard error.

\section{$M_{2}$ variation}

Phenotypic variation. Variation in root color and carotene content was observed in $\mathbf{M}_{2}$ progeny, as was seen in $M_{1}$, but variation in floral morphology, leaf color, leaf length, and shoot number was not observed in $\mathbf{M}_{2}$ progeny of variant $\mathbf{M}_{1}$ plants.

Level of variation in root weight, TDS, and total carotene. A significant amount of variation in root weight (higher or lower than the control) was observed in all gamma ray treatments of dry seed (Table 1), where $60 \%$ of the plants surviving $40 \mathrm{krad}$ differed from the control. Considerable variation was also seen in TDS, where the level was as high as $33 \%$ at the 10- and 20-krad doses. No significant variation in carotene content was induced in the dry seed experiment.

Less variation in the root weight and more variation in TDS (up to $70 \%$ of the plants) appeared in plants from irradiated germinating seed than was seen from dry seed treatments (Table 1). Some variation $(20 \%)$ in carotene content was seen in the $20-\mathrm{krad}$ treatment.

More variation for carotene content was observed in plants regenerated from irradiated tissue cultures than from seed treatments (Table 1). Variation in root weight and TDS was also observed in all doses with levels comparable to that found in germinating seed.

Distribution of variation. In the $\mathrm{M}_{2}$ generation, variants exceeding control root weight, TDS, and carotene content by at least 1 LSD outnumbered those less than the control for all cases except TDS for dry-irradiated seed (Table 2). Most of the root weight and TDS variants were $\pm 2 \mathrm{LSD}$, while over half of the carotene variants differed from the control by $>2$ LSD.

Enhancement of root weight by gamma irradiation. An interesting phenomenon regarding the root weight was observed in all three experiments (Fig. 5). Average root weight increased with increasing gamma ray doses. This increase was more pronounced from irra- diating dry seed, where root weight increased by about $35 \%$ above the control at the 20-krad dose.

\section{Discussion}

Gamma irradiation had significant effects on carrot plants generated from tissue cultures and seed. Germination of carrot seed was accelerated and growth of $\mathrm{M}_{1}$ plants was enhanced at low doses of gamma irradiation. Regeneration of carrot plants from tissue culture was also enhanced at low doses of gamma irradiation. Variation in $M_{1}$ and $M_{2}$ plants increased with gamma irradiation.

The stimulatory effects of gamma radiation on seeds, observed in $\mathrm{M}_{1}$ plants of this study, is similar to that reported by others (Iqbal et al., 1974; Kuzin et al., 1986; Livingston and Stettler, 1973; Maherchandani, 1975; Shull and Mitchell, 1933). Acceleration of seed germination by low doses of ionizing radiation has been attributed to many factors. Maherchandani (1975) attributed the promotion of Avena fatua L. seed germination to the increase in oxygen uptake following irradiation with low doses of gamma rays, which resulted in the production of organic and inorganic peroxy radicals, which led to breaking seed dormancy. Although carrot has no seed dormancy, low doses of gamma irradiation in the present study accelerated seed germination. The inhibition of seed germination at high doses may have resulted from a damage to chromosomes and subsequent mitotic retardation similar to those seen in irradiated carrot tissue cultures (Al-Safadi and Simon, 1990).

Radiation-induced stimulation of plant growth has been observed by several investigators. Fowler and MacQueen (1972) hypothesized that most of the reported stimulatory effects of low doses of radiation result in increased seedling vigor, early modifications in axillary bud development, and changes in initial rate of floral differentiation. Bakr et al. (1976) reported that irradiation increased chlorophyll concentration in the leaves and the dry weight of shoots of corn seedlings. This could explain the increase in leaf color observed in carrot. Woodstock and Justice (1967) reported an increase in rate of respiration of corn plants at low doses of gamma irradiation. An increase in $\mathrm{M}_{1}$ carrot and root weight in the seed experiment at 1-krad dose was observed in our study. Similar results were reported for other crops. Srivastava and Tyagi, (1986) observed a significant increase in palmarosa (Cymbopogon martinii) plant height, leaf number, total herbage yield, and essential oil production at 10 and 15 krads of gamma radiation. The stimulation of plant growth at low doses of irradiation was attributed to an increase in auxin levels, whereas the

Table 1. $\mathrm{M}_{2}$ variation in root weight, total dissolved solids (TDS), and total carotene content in irradiated carrots. Values represent percentage of total plants that were significantly different from the control at $P=0.05$.

\begin{tabular}{lcccc}
\hline \hline Experiment & $\begin{array}{c}\text { Dose } \\
(\mathrm{krads})\end{array}$ & $\begin{array}{c}\text { Root } \\
\text { wt }(\%)\end{array}$ & TDS $(\%)$ & Carotene $(\%)$ \\
\hline Dry seed & 5 & 45 & 20 & 0 \\
& 10 & 50 & 33 & 0 \\
Germinating seed & 20 & 33 & 33 & 0 \\
& 40 & 60 & 28 & 0 \\
Tissue culture & 5 & 22 & 48 & 0 \\
& 10 & 15 & 70 & 0 \\
& 20 & 44 & 66 & 33 \\
& 5 & 25 & 41 & 0 \\
\hline
\end{tabular}


Table 2. Distribution of $\mathrm{M}_{2}$ variants that significantly differed from to the control. Control mean values are root weight $=24 \mathrm{~g}$, total dissolved solids $($ TDS $)=9.4 \%$, and carotene content $=135 \mu \mathrm{g} \cdot \mathrm{g}^{-1}$ fresh weight. LSD values are root weight $=6.4$, TDS $=0.29$, and carotene $=26.2$.

\begin{tabular}{|c|c|c|c|c|c|c|}
\hline $\begin{array}{l}\text { Variant category } \\
\text { (in LSD) }\end{array}$ & $<3$ & -2 to 3 & -1 to 2 & 1 to 2 & 2 to 3 & $>3$ \\
\hline \multicolumn{7}{|c|}{ Root weight (\%) } \\
\hline Dry seed & 20.0 & 0.0 & 20.0 & 10.0 & 40.0 & 10.0 \\
\hline Germinating seed & 0.0 & 0.0 & 25.0 & 41.6 & 25.0 & 8.4 \\
\hline Tissue culture & 0.0 & 0.0 & 41.6 & 33.4 & 25.0 & 0.0 \\
\hline \multicolumn{7}{|c|}{$\operatorname{TDS}(\%)$} \\
\hline Dry seed & 20.0 & 10.0 & 40.0 & 10.0 & 20.0 & 0.0 \\
\hline Germinating seed & 7.7 & 34.6 & 3.8 & 26.9 & 26.9 & 0.0 \\
\hline Tissue culture & 0.0 & 0.0 & 41.6 & 41.6 & 16.6 & 0.0 \\
\hline \multicolumn{7}{|c|}{ Carotene (\%) } \\
\hline Dry seed & 0.0 & 0.0 & 0.0 & 0.0 & 0.0 & 0.0 \\
\hline Germinating seed & 0.0 & 0.0 & 0.0 & 40.0 & 40.0 & 20.0 \\
\hline Tissue culture & 0.0 & 12.5 & 25.0 & 12.5 & 25.0 & 25.0 \\
\hline
\end{tabular}

reduction in plant growth at high doses was explained on the basis of auxin destruction, changes in ascorbic acid content, and physiological and biochemical disturbances (Srivastava and Tyagi, 1986). This stimulation of plant growth at low doses of irradiation could be used to increase yield of crops by as much as $20 \%$ (Fig. 3).

Survival of carrot plants from seed in our study was reduced by $>50 \%$ at the 10 - and $20-\mathrm{krad}$ doses. On the other hand, survival in the greenhouse of plants regenerated from irradiated tissue cultures was better than that of plants regenerated from unirradiated cultures. This increase in survival rate could be attributed to a selection by gamma radiation for cells resistant to radiation leading to the regeneration of vigorous embryos and later to vigorous plants. The fertility of carrot plants was also reduced by almost $50 \%$ at a $20-\mathrm{krad}$ dose. These two factors (survival and fertility of plants) can be used to determine the largest possible dose to be applied and as a measure of the relative effect of the mutagen on inducing variation in the $M_{2}$ (Doll and Sandfaer, 1968). Such a dose for carrot is estimated between 10 and 20 krads.

The significant amount of variation observed in $\mathrm{M}_{2}$ suggests that gamma irradiation was very effective in inducing variation in carrots. Depending on irradiated plant material, observed variation

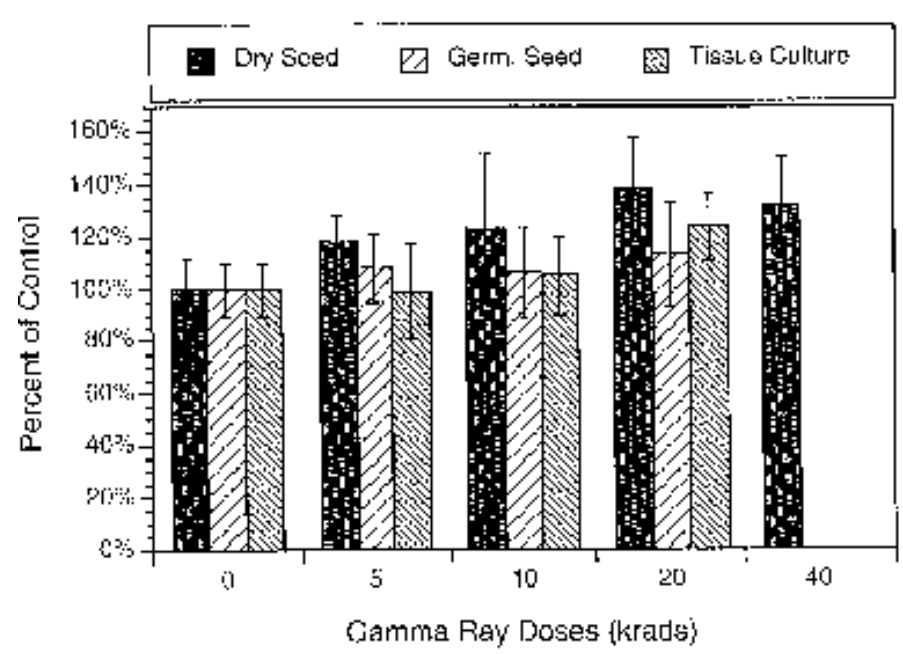

Fig. 5. $\mathrm{M}_{2}$ root weight (percent of control) with increasing gamma ray dosage in all three experiments. All values are adjusted to a percent of control. Control value $=24 \mathrm{~g}$. Values represent the means of treatments \pm standard error. ranged from $8 \%$ to $60 \%$ of total plants (Fig. 6). Much of the variation occurred in TDS ( $28 \%$ to $62 \%$ of the $\mathrm{M}_{2}$ plants) followed by root weight ( $24 \%$ to $55 \%)$. Less variation was observed in the total carotenes ( $0 \%$ to $30 \%)$ and none in the sugar type (reducing vs. nonreducing). Differences in the amount of observed variation may reflect the number of genes controlling those characters. The effective selection for TDS over five cycles of recurrent selection (Stommel and Simon, 1989) suggests the involvement of many genes in the control of this trait. About five genes are involved in the carotene synthesis (Buishand and Gabelman, 1979), although polygenic control of high carotene content is evident (Simon and Wolff, 1987). Only one gene is known to control sugar type in carrots (Freeman and Simon, 1983) and it is present in the recessive form in the line used in this study. It is unlikely that a mutation would occur from the recessive to dominant form, which may explain why no variation in the sugar type (reducing vs. nonreducing) was observed. In addition to a genetic change, nongenetic effects could also explain $\mathrm{M}_{2}$ variation.

An interesting observation was the increase in $\mathrm{M}_{2}$ root weight with the increase in irradiation dosage (Fig. 5). It is doubtful that

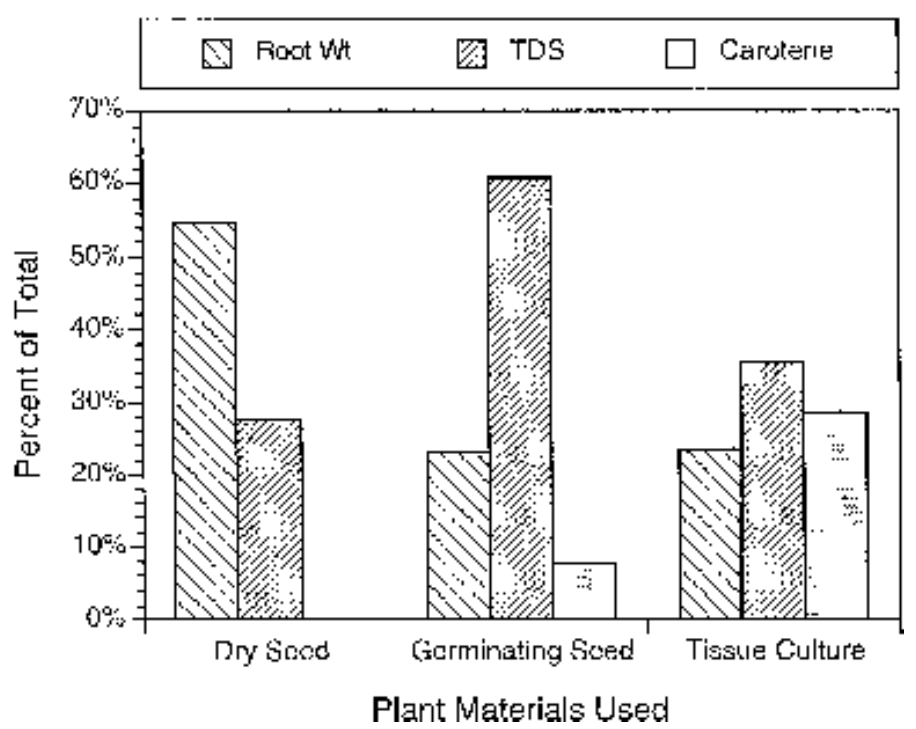

Fig. 6. Types of $\mathrm{M}_{2}$ carrot variation as a function of plant material irradiated. Bars represent the cumulative $\mathrm{M}_{2}$ variation of all doses within every experiment. 
mutations leading to an increase in root weight would have occurred with increasing gamma ray doses. One explanation is that irradiation played a selective role when seed was irradiated. Although the plant materials used were very inbred, it is possible that only vigorous seedlings survived, leading to vigorous plants. It is not clear why, then, controls would not also demonstrate this type of selection. A physiological stimulus carried over to the $M_{2}$ could also explain this observation.

In spite of the presence of chromosomal abnormalities in $\mathbf{M}_{1}$ control tissue culture (Al-Safadi and Simon, 1990), no significant variation (somaclonal variation) was observed in $\mathbf{M}_{2}$ families derived from plants regenerated from the control cultures. This is in contrast to studies in other species (Binns, 1981; Carlson, 1970; Evans et al., 1984; Larkin et al., 1984). Novak et al. (1988) reported a higher frequency of $R_{2}$ variation (somaclonal variation) than $M_{2}$ variation (induced by gamma irradiation) in maize. In our study, the use of tissue culture as a plant material for irradiation produced variation equal to that produced by irradiating germinating seed.

Several types of phenotypic variation observed in $M_{1}$ were not seen in $M_{2}$. This suggests that $M_{1}$ variation was probably a consequence of a physiological effect of gamma radiation. Another explanation is that the variation was a result of chromosomal aberrations that could not be transferred to $M_{2}$ because of high sterility associated with these plants.

This study indicates that gamma irradiation may be effective in inducing heritable variation in carrot. The heritable nature of the observed variation can only be established in subsequent generations. Although they were sought, no clear simply inherited mutants were observed in the $\mathbf{M}_{2}$ generation or in self-pollinated $\mathbf{M}_{3}$ progenies (data not presented). In contrast to radiation-induced variation, no tissue-culture induced, somaclonal variation was observed. Perhaps this is because no selection pressure for specific phenotype was applied.

\section{Literature Cited}

Al-Safadi, B. and P.W. Simon. 1990. The effects of gamma irradiation on the growth and cytology of carrot (Daucus carota L.) tissue culture. Environ. Expt. Bot. 30:361-371.

Bakr, A.M., N.E. Ashour, S.Z. El-Basyouni, and A.M. Sayed. 1976. Response of the photosynthetic apparatus of corn (Zea mays) to presowing seed treatment with gamma rays and ammonium molybdate. Environ. Expt. Bot. 16:217-222.

Binns, A.N. 1981. Developmental variation in plant tissue cultures. Environ. Expt. Bot. 21:325-332.

Buishand, J.G. and W.H. Gabelman. 1979. Investigations on the inheritance of color and carotenoid content in phloem and xylem of carrot roots (Daucus carota L.) Euphytica 28:611-632.

Carlson, P.S. 1970. Induction and isolation of autotrophic mutants in somatic cell cultures of Nicotiana tabacum. Science 168:487-489.

Doll, H. and J. Sandfaer. 1968. Mutagenic effect of gamma rays, diethyl sulphate, ethyl methanesulphonate, and various combinations of gamma rays and the chemicals. IAEA-SM 121/5:195-206.

Estramareix C., P. Rate, F. Boulanger, and F. Richaud. 1986. Multiple mutations in the transferred regions of the Agrobacterium rhizogenes root-inducing plasmids. Plasmid 15:245-247.

Evans, A.D., W.R. Sharp, and H.P. Medina-Filho. 1984. Somaclonal and gametoclonal variation. Amer. J. Bot. 71:759-774.
Fowler, D.B. and K.F. MacQueen. 1972. Effects of low doses of gamma radiation on yield and other agronomic characters of spring wheat (Triticum asetivum) Radiat. Bot. 12:349-353.

Freeman, R.E. and P.W. Simon. 1983. Evidence for simple genetic control of sugar type in carrot (Daucus carota L.) J. Amer. Soc. Hort. Sci. 108:50-54.

IAEA 1989. 25 years of plant breeding and genetics section of the joint FAO/IAEA division, Vienna. Mutation Breeding Nwsl. 34:1-2.

Iqbal, J., M. Kutacek, and V. Jiracek. 1974. Effects of acute gamma irradiation on the concentration of amino acids and protein-nitrogen in Zea mays. Radiat. Bot. 14:156-172.

Kuzin, A.M., M.E. Vagabova, M.M. Vilenchik, and V.G. Gogvadze. 1986. Stimulation of plant growth by exposure to low level gammaradiation and magnetic field, and their possible mechanism of action. Environ. Expt. Bot. 26:163-167.

Larkin, P.J., S.A. Ryan, R.I.S. Brettell, and W.R. Scowcroft. 1984 Heritable somaclonal variation in wheat. Theor. Appl. Genet. 67:443455.

Livingston, G.K. and R.F. Stettler. 1973. Radiation-induced stimulation of pollen-tube elongation in douglas-fir. Radiat. Bot. 13:65-72.

LoSchiavo, F., L. Pitto, G. Giuliano, G. Torti, V. Nuti-Ronchi, D. Marazziti, R. Vergara, S. Orselli, and M. Terzi. 1989. DNA methylation of embryogenic carrot cell cultures and its variations as caused by mutation, differentiation, hormones, and hypomethylating drugs. Theor. Appl. Genet. 77:325-331.

LoSchiavo, F., G. Giovinazzo, and M. Terzi. 1983. 8-Azaguanine resistant carrot cell mutants and their use as universal hybridizers. Mol. Gen. Genet. 192:326-329.

Maherchandani, N. 1975. Effects of gamma radiation on the dormant seeds of Avena fatua L. Radiat. Bot. 15:439-443.

Miller, P.D., K.C. Vaughn, and K.G. Wilson. 1984. Ethyl methanesulphonate-induced chloroplast mutagenesis in crops. J. Heredity 75:8692.

Novak, F.J., S. Daskalov, H. Brunner, M. Nesticky, R. Afza, M. Dolezelova, S. Lucretti, A. Herichova, and T. Hermelin. 1988. Somatic embryogenesis in maize and comparison of genetic variability induced by gamma radiation and tissue culture techniques. Plant Breed. 101:66-79.

Shull, C.A. and J.W. Mitchell. 1933. Stimulative effects of X-rays on plant growth. Plant Physiol. 8:287-296.

Simon, P.W. and R.E. Freeman. 1985. A rapid method for screening reducing sugar in carrot roots. HortScience 20:133-134.

Simon, P.W. and C.E. Peterson. 1984. Controlled pollination in carrot. Plant Mol. Biol. Rpt. 2:43-44.

Simon, P.W. and X.Y. Wolff. 1987. Carotenes in typical and dark orange carrots. J. Agr. Food. Chem. 35:017-1022.

Simon, P.W., C.E. Peterson, and W.H. Gabelman. 1990. B493 and B9304, carrot inbreds for use in breeding, genetics, and tissue culture. HortScience 25:815.

Srivastava, H.K. and B.R. Tyagi. 1986. Effects of seed irradiation on yield and quality of essential oil in Palmarosa (Cymbopogon Martinii Stapf.) Euphytica 35:369-380.

Stommel, J.R. and P.W. Simon. 1989. Phenotypic recurrent selection and heritability estimates for total dissolved solids and sugar type in carrot. J. Amer. Soc. Hort. Sci. 114:695-699.

Sung, Z.R. 1976. Mutagenesis of cultured plant cells. Genetics 84:51-57. Templeton-Somers, K.M., W.R. Sharp, and R.M. Pfister. 1981. Selection of cold resistant cell lines of carrot. Z. Planzenphysiol. 103:139-148.

Woodstock, L.W. and O.L. Justice. 1967. Radiation-induced changes in respiration of corn, wheat, sorghum and radish seeds during initial stages of germination in relation to subsequent seedling growth. Radiat. Bot. 7:129-136. 